\title{
RECONSTRUCTION OF INTEGRATIVE ISLAMIC EDUCATION IN THE TRANSFORMATIVE PROFETICAL EDUCATION FRAMEWORK
}

\author{
Muhamad Khoirul Umam \\ STAI Badrus Sholeh Purwoasri Kediri \\ khoirul_umam2426@yahoo.co.id
}

\begin{abstract}
Scientific disruptions today, or appearing on the surface in a wide variety of scientific integration projects known as Islamization of science, integralization of science, or interconnections create complex problems with the many ideas of integrative education through transformative prophetic education. Various phenomena of the problem then there are two things that become important points that we can make the lens to see the phenomenon of illness of education today. Firstly, Education has no soul in question in education here about re-presenting the mission of religious prophetic values to be presented to the public sphere. Secondly, the existence of human model as role model (uswatun hasanah). In education, especially character education that has become an agreement decision making education of Indonesia must display the human figure in the role model or model that must be imitated as according to the output of character education itself. But it aims to describe the implementation of integration of Islamic education in Islamic educational institutions from the perspective of integration between educational institutions, family and community and prophetic-based with transformative values. This research yields One offer of thinking about alternative education which is expected to reduce deadlock in developing integrative education with standard and figure of really strong and irrefutable model that is Prophet Muhammad Saw and return to activity, feeling, thinking in interpreting Al- Quran and Sunnah.
\end{abstract}

Keywords: integrative, profetic, transformative

\section{PENDAHULUAN}

Era disrupsi ini diinterprestasikan bagaimana kehidupan manusia banyak dipengaruhi materialisme, digitalisme dan kapitalisme baru menjadi kekuatan raksasa yang dengan perlahan-lahan telah mengikis bangsa ini menjadi bangsa penurut, tunduk pada kemajuan teknologi, mengagungkan pasar (marketing) dan menjadi bangsa konsumtif. Di samping itu, faktor permasalahan dalam negeri tidak mau kalah, korupsi yang membudaya dan terus ber-generasi seperrti amoba yang mengakar sampai pelosok bawah, akhlak anak bangsa yang memperihatinkan, kemiskinan yang disebabakan kegagalan dalam ketahanan pangan, kebodohan diakibatkan kurangnya wacana literasi yang kalah akan teknologi yang mengarah ke uforia, kesehatan dampak munculnya 
varian penyakit baru yang belum dapat ditangani karena kurangnya ahli kesehatan adalah masalah yang pelik dan kusut untuk kita urai dari mana akar permasalahan sebenarnya. Permasalahan-permasalahan itu semua memberikan eksistensi negatif yang berakibat pada runtuhnya sendi-sendi bangsa ini.

Bidang politik, ekonomi, agama, sosial-budaya dan termasuk pendidikan merupakan sendi kehidupan bangsa ini yang telah terkena imbas dari permasalahan yang diciptakan manusia global (internasional) maupun lokal (bangsa sendiri). Dengan demikian, kebanyakan orang hanya memaknai kehidupan dengan kaca mata realitas untuk menyadari apa permasalahan yang terjadi. Problem manusia disrupsi saat ini begitu kompleks, manusia yang semula merdeka yang seolah merasa menjadi pusat dari segala sesuatu, kini telah diturunkan derajatnya menjadi tak lebih dari sebagai bagian dari mesin- mesin raksasa teknologi digital. Karena proses inilah, maka pandangan tentang manusia yang insani menjadi tereduksi. Nilai manusia yang insani kini terdegradasi oleh proses bekerjanya teknologi digital.

Pendidikan itu memang mahal, karena pendidikan menjadi alat komersialisasi dan pendidikan gagal membentuk karakter manusia seutuhnya adalah beberapa inventarisasi masalah yang sering muncul di arena publik. Prof. Dr. Wuryadi, MS, Ketua Dewan Pendidikan DIY menginventarisir beberapa permasalahan dalam pendidikan Indonesia. Permasalahan itu adalah arus globalisasi dan liberalisasi pendidikan yang menjauhkan dari aspirasi pendidikan untuk semua, adanya upaya secara sistematis untuk menempatkan institusi pendidikan di Indonesia lebih sebagai corporate institution, adanya upaya untuk menyebarluaskan logika corporateness, yaitu tidak ada pendidikan yang bermutu tanpa biaya mahal dan adanya upaya secara sistematis untuk memasang kriteria mutu sebagai pintu untuk keterbukaan institusi pendidikan di Indonesia bagi campur tangan global. Di era reformasi, dunia pendidikan tinggi di Indonesia memasuki babak baru, yaitu kapitalisasi perguruan tinggi terutama perguruan tinggi Islam yang mulai bangkit.

Dari berbagai fenomena permasalahan ini maka ada dua hal yang menjadi point penting yang bisa kita jadikan lensa untuk melihat fenomena sakitnya pendidikan saat ini. Pertama, Pendidikan belum mempunyai jiwa yang dimaksud dalam pendidikan disini tentang menghadirkan kembali misi nilai-nilai kenabian keagamaan untuk disajikan ke ruang publik. Mengenai hal ini, kita tidak lagi berdebat mengenai dikotomi pendidikan umum dan pendidikan agama dalam legal-formal. Akan tetapi kita berbicara semangat yang menjiwai pendidikan itu sendiri yang diantaranya pendidikan yang humanis dan dapat memainkan peran liberasi (pembebasan) yang membebaskan dari segala penindasan, kebodohan, kemiskinan. Kedua, adanya model manusia sebagai tauladan (uswatun hasanah).

Dalam pendidikan, khususnya pendidikan karakter yang telah menjadi kesepakatan decision making pendidikan Indonesia harus menampilkan sosok manusia yang di jadikan panutan atau model manusia yang harus ditiru sebagaimana sesuai dengan output dari pendidikan karakter itu sendiri. $\mathrm{Hal}$ ini bertujuan untuk mendeskripsikan penyelenggaraan integrasi pendidikan Islam di lembaga pendidikan Islam dari sudut pandang keterpaduan antara lembaga pendidikan, keluarga dan masyarakat serta berbasis kenabian dengan nilai-nilai transformatif. 


\section{KONSEPTUALISASI PROFETIK}

Masalah pendidikan sudah lama menjadi pokok diskusi masyarakat Indonesia, khususnya para pengamat dan pakarnya. Diskusi-diskusi tersebut telah menghasilkan berbagai definisi tentang hakekat, peranan serta pentingnya pendidikan. Sejauh perkembangannya selama ini, baik secara konseptual maupun teknisnya di lapangan, pendidikan telah mengalami beberapa fase perubahan. Hal itu disebabkan karena pendidikan selalu mencoba melahirkan konsep-konsep baru dalam mengatasi berbagai persoalan yang muncul di dalamnya. Namun tidak bisa dipungkiri bahwa pendidikan di Indonesia justru terjebak ke dalam sebuah cara pandang dan ideologi yang sebagian besar diadopsi dari Barat. Implikasinya adalah pendidikan akan semakin kehilangan ruhnya. Oleh sebab itu, dibutuhkan sebuah sintesis yang paling memungkinkan dalam menyelesaikan beberapa persoalan tersebut.

Pemaknaaan profetik berawal dari bahasa Inggris prophet (nabi) sedangkan prophetic bermakna (kenabian). ${ }^{1}$ Yaitu sifat nabi yang mempunyai ciri sebagai manusia yang ideal secara spiritual-individual, tetapi juga menjadi pelopor perubahan, membimbing masyarakat ke arah perbaikan dan melakukan perjuangan tanpa henti melawan penindasan. Dalam sejarah, Nabi Ibrahim melawan Raja Namrud, Nabi Musa melawan Fir'aun, Nabi Muhammad yang membimbing kaum miskin dan budak belia melawan setiap penindasan dan ketidakadilan, mempunyai tujuan untuk menuju kearah pembebasan. ${ }^{2}$ Menurut Ali Syari'ati dalam Hilmy para nabi tak hanya mengajarkan dzikir dan do'a tetapi mereka juga datang dengan suatu ideologi pembebasan. ${ }^{3}$ Dalam Oxford Dictionary, prophetic merupakan: Of pertaining or paper to a prophet or prophecy: having the character or function of a prophet, characterized by containing or of the nature of prophecypredictive.

Kata prophetic yang berawal dari bahasa inggris itu berasal dari bahasa yunani prophetes yang memiliki arti sebuah kata benda untuk menyebut seseorang berbicara awal atau seseorang yang memproklamasikan diri dan dapat berarti juga seseorang yang berbicara masa depan. ${ }^{4}$ Jadi pemaknaan profetik memiliki sifat atau kecirian seperti nabi atau bersifat prediktif, memperkirakan, yang diartikan sebagai kenabian.

Selanjutnya kenabian terkandung makna dalam segala hal ihwal yang berhubungan dengan seseorang yang telah memperoleh potensi kenabian. ${ }^{5}$ Potensi kenabian dapat menginternalisasi dalam diri setelah melakukan proses pendidikan dengan langkah-langkah pengelolaan (manajemen) jiwa serta raga yang didahului pendasaran filosofi yang disandarkan pada nilai-nilai kenabian dalam Al Qur'an, Sunnah, dan ljtihad dengan berbagai upaya pemikiran yang mencerminkan dan prediksi sampai kepada penelitian empiris.

\footnotetext{
${ }^{1}$ M. Dagum, Kamus Besar Ilmu Pengetahuan (Jakarta: Lembaga Pengkajian Nusantara, 2006), 897.

2 Muhammad Basyam Rusydi Az-Zain, Sekolah Para Nabi 1 \& 2 (Yogyakarta: Pustaka Marwa, 2007),

3 Ali Shari'ati, Humanisme: Antara Islam dan Mazhab Barat, terj. Husein Anis al- Habshi (Bandung: Pustaka Indah, 1996), 119.

${ }^{4}$ Moh. Roqib, Filsafat Pendidikan Profetik: Pendidikan Islam Integrative dalam Persfektif Kenabian Muhamad (Purwokerto: An-najah Press, 2016), 26-37.

${ }^{5}$ Hamdani Bakran Adz-Dzakiey, Prophetic Psychology: Psikologi Kenabian Menghidupkan Potensi dan Kepribadian Kenabian dalam diri (Yogyakarta: Pustaka Al Furqon, 2007), 44.
} 
Secara historisas pengetahuan serta pemikiran profetik diperbincangkan sangat intensif oleh ibnu arabi (II65-I24I) dan Surahwadi (II55-II9I) yang secara garis besar mengkritik pengetahuan seerta pemikiran yunani serta menawarkan profetik yang intinya adalah dialektika manusia, alam dan Tuhan dikembangkan untuk mendapatkan produk pemikiran baru sebagai alternatif pemikiran barat yang dinyatakan gagal. Kemudian di Indonesia lebih lanjut oleh Moh Roqib dalam pemikiran profetiknya, memunculkan gagasan yang mengarah kepada pendidikan dan menjadi sebuah teori baru pendidikan profetik, yang terilhami dari pemikiran Kuntowijoyo yang menjadi dasar profetik (humanisasi, liberasi, dan transendensi) yang dijadikan dalam pengembangan pendidikan profetiknya. Tiga pilar dasar profetik itu menjadi keharusan berdialektika dengan budaya lokal agar tetap kokoh karena tidak berhadapan dengan budaya setempat selama budaya tersebut tetap dalam bingkai akhlakul karimah atau etika.

Budaya sebagai landasan gerak langkah perilaku individu ataupun kelompok sosial harus dibangun dengan mempertahankan yang positif dan mengambil secara kreatif hal baru yang lebih baik dan bermanfaat dalam kehidupan. ${ }^{6} \mathrm{Di}$ samping itu pula perlu di dasari oleh cara pandang nilai-nilai kenabian yakni: I) dasar tauhid menjadikan ilmu sosial, kebudayaan, dan ilmu pengetahuan dan teknologi tidak terpisahkan dengan filsafat dan tasawuf; 2) dasar nabi (prophet) sebagai sosok pandangan model uswatun hasanah serta seorang manusia yang diberi kemampuan oleh Tuhannya; 3) dasar ilmu sebagai medan sentuh pemikiran akal manuisa yang disandarkan kepada Allah.

\section{SUDUT PANDANG VALUES RELIGIOUS SEBAGAI PEMBENTUKAN KARAKTER}

Pendidikan Islam bukan sekedar proses penanaman nilai-nilai karakter untuk membentengi diri dari eksistensi disrupsi. Tetapi yang paling penting adalah bagaimana nilai-nilai karakter yang telah ditanamkan pendidikan Islam tersebut mampu berperan sebagai kekuatan pembebas (liberating force) dari himpitan kekurangan finansial, kekurangan keilmuan, keterbelakangan sosial budaya dan ekonomi. ${ }^{7}$ Kandungan materi pelajaran dalam pendidikan Islam yang masih berkutat pada tujuan yang lebih bersifat ortodoksi diakibatkan adanya kesalahan dalam memahami konsep-konsep pendidikan yang masih bersifat dikotomis; yakni pemilahan antara pendidikan agama dan pendidikan umum (sekuler), bahkan mendudukkan keduanya secara diametral.

Pendidikan Islam merupakan bagian yang tidak terpisahkan dari sistem pendidikan di Indonesia. Hal ini diwujudkan dengan adanya sekolah-sekolah yang bercirikan Islam seperti Bustanul Atfal (TK), Madrasah Ibtidaiyah (SD), Madrasah Tsanawiyah (SMP), Madrasah Aliyah (SMU), dan Perguruan Tinggi Islam baik dikelola swasta ataupun negeri, serta adanya pesantren-pesantren baik salafi maupun modern. Realitas ini merupakan sesuatu yang menggembirakan bagi perkembangan umat Islam untuk waktu yang akan datang, karena diharapkan dengan munculnya sekolah-sekolah Islam akan memberikan dampak yang positif bagi terciptanya generasi yang Islami. Kondisi lain akan tercipta juga

\footnotetext{
${ }^{6}$ Moh. Roqib, Filsafat Pendidikan Profetik..., 34

${ }^{7}$ Ahmad Syafii Ma'arif, Islam dalam Bingkai Kemanusiaan dan Keindonesiaan (Bandung: Mizan, 2009), 231.
} 


\section{Qnd Proceedings \\ Annual Conference for Muslim Scholars KOPERTAIIS WILAYAH IV SURABATA

ketika pendidikan Islam melalui sekolah-sekolahnya tidak menerapkan pendidikan seutuhnya seperti pernah disinggung oleh Chabib Thoha bahwa tujuan pendidikan Islam adalah pembentukan insan kamil (manusia menyeluruh) artinya pendidikan Islam tidak hanya mementingkan satu aspek pengetahuan saja, akan tetapi pendidikan apapun bentuknya pendidikan itu paling tidak berorientasi pada tiga aspek dasar seperti dikatakan Blomm, yaitu berorientasi pada aspek kognitif, afektif, dan psikomotorik.

Di samping itu fenomena lain yang menjadi kekhawatiran ialah semakin banyaknya kasus narkoba, minum-minuman keras, kenakalan remaja, generasi itu kemudian setelah menjadi pejabat akan korup dan masih banyak kejahatan-kejahatan lainnya. Hal inilah yang perlu mendapatkan perhatian serius agar Islam tidak hanya sekedar simbol-simbol akan tetapi mempunyai subtansi menciptakan bangsa yang kuat, meminjam dari filsafat jawa gemah ripah loh jinawi tata tentrem kertoraharjo.

Hasil pencarian peneliti untuk menjawab pendidikan kita yang nantinya dengan cara pandang nilai-nilai religius dalam pembentukan karakter yang ideal mengarah kepada firman Allah Swt. Sebagaimana termaktub dalam surat al Ahzab ayat 21. Dalam ayat tersebut memberikan petunjuk bahwa Rasulullah Saw. merupakan contoh model yang baik bagi manusia di berbagai bidang, terutama dalam bidang pengembangan pendidikan karakter. Nilai kenabian tersebut atau juga disebut sebagai nilai profetik itulah yang harus menjadi orientasi manusia dalam pengembangan karakter (character building) dirinya.

Profetik sendiri berarti nilai kenabian yang digali dari cara Rasulullah Saw. semasa hidupnya. Nilai profetik pun masih dipandang sebagai sebuah konsep karakter paling sukses dan adaptatif dalam membentuk tatanan kehidupan manusia berkualitas. Nilai ini selayaknya diimplementasikan ke dalam model kehidupan di berbagai lingkup: organisasi sosial, perdagangan, pendidikan, pemerintahan, dan lainnya. ${ }^{8}$

Menurut Ustadz Syafi'i Antonio, nilai profetik adalah esensi yang sepatutnya mendasari gerak langkah manusia dalam beraktivitas apapun bentuknya (berdagang, berpolitik, berkeluarga, dan sebagainya). Namun realita yang ada, masyarakat Muslim Indonesia justru melupakan esensi dari sifat-sifat kerasulan Nabi Muhammad Saw. Sosok Rasulullah yang tidak dibawa dalam kehidupan sosial-ekonomi-politik masyarakat. Contoh kasus ketika seseorang berdagang, ia lupa bagaimana cara berdagang Rasulullah. Saat seseorang berpolitik, ia lupa bagaimana cara berpolitik Rasulullah. Nabi Muhammad Saw. menjadi sosok yang dekat, namun esensinya sebagai sosok suri teladan menjadi terlupakan

Nilai-nilai profetik dapat dipelajari dari sifat-sifat kenabian yang ada pada diri Rasulullah Saw. Berikut peneliti jabarkan sifat-sifat kenabian Rasulullah Saw. yang bisa menjadi inspirasi bagi seorang muslim muda dalam pembentukan jati diri karakter yang Islami: ${ }^{9}$ I) Sidiq (integrity) secara sederhana sifat sidiq dapat diartikan sebagai kejujuran. Namun secara luas, sidiq juga merupakan sebuah integritas moral yang dimiliki oleh seseorang. Kejujuran dinilai sebagai sebuah modal mendasar dalam membentuk integritas. 2) Amanah (responsible) juga dapat diartikan sebagai sifat terpercaya. Sifat ini

\footnotetext{
${ }^{8}$ Mujtahid, Tujuh Karakteristik Kepemimpinan Profetik (Malang: UIN Maliki, 2011).

${ }^{9}$ Ibid.,
} 
melatih seseorang pada sifat bertanggung jawab dan dapat diandalkan. Karakter amanah akan dapat mengasah seseorang dalam memilah dan memilih antara kepentingan pribadi dan kepentingan publik. 3) Fathanah (smart) adalah karakter seseorang dengan kualitas diri (capacity building) yang baik. Kualitas diri mencakup pada kecerdasan spiritual dan intelektual, dan keterampilan (skillful). 4) Tabligh (communicative) dapat pula diartikan sebagai kemampuan komunikasi yang efektif. Dengan komunikasi yang efektif, maka seseorang dapat dengan mudah menyampaikan visi dan misinya kepada orang lain.

Keempat sifat itulah yang peneliti sebutkan sebagai sifat profetik atau kenabian. Sifat-sifat yang sepatutnya menjadi pedoman seseorang untuk membentuk karakter diri (character building) demi meningkatkan kualitas diri secara vertikal (hablun min Allah) maupun horizontal (hablun min al-nas). Nilai-nilai ini pulalah yang berperan dalam mengarahkan tujuan hidup umat Muslim Indonesia. Jati diri umat Islam yang selama ini terkikis dapat kembali dibentuk. Keterpojokan umat Islam Indonesia karena tidak dapat menciptakan kondisi masyarakat yang adil dan sejahtera dapat diputarbalikan. Tentu dengan senantiasa berdoa dan mengharap kemudahan dari Allah Swt. dalam melakukan perjuangan dan perubahan bagi agama, nusa, dan bangsa.

\section{PILAR-PILAR PENDIDIKAN BERDASAR FRAME NILAI-NILAI KENABIAN}

Peneliti memunculkan bahwa pilar-pilar pendidikan profetik dapat diambil dari al Iman, al Islam, dan al Ihsan. Beriman kepada Allah subhanhu wa ta'alaa adalah membenarkan dengan yakin akan adanya Allah subhanhu wa ta'alaa, membenarkan dengan yakin akan keesaan-Nya, baik dalam perbuatan-Nya menciptakan alam makhluk seluruhnya, maupun dalam menerima ibadat segenap makhluk-Nya, kemudian juga membenarkan dengan yakin, bahwa Allah swt memiliki sifat sempurna, suci dari segala sifat kekurangan dan suci pula dari menyerupai segala yang baru (makhluk). Sebuah pembenaran yang terealisir dalam hati, lisan, dan amal perbuatan. Inti dari rukun iman yakni bahwa menjadikan manusia yang ilma yaqin, ainal yaqin, haqul yaqin, dan al kamil.

Al Islam adalah bentuk interpretasi dari rukun Islam yang lima yakni, mengucap kalimat sahadat, melaksanakan sholat lima waktu, mengerjakan puasa wajib pada bulan ramadhan, membayar zakat, dan berhaji bila mampu. Di samping itu subtansi yang sangat penting yakni dalam Islam ada tingkatan manusia yang harus dilalui yakni syariat, thoriqoh, hakikat dan ma'rifat yang perlu dibahas secara luas. Sementara Al Ihsan bahwa Allah SWT mewajibkan kepada kaum muslimin untuk senantiasa berbuat ihsan. Berbuat ihsan yang dimaksud dalam hadits di atas adalah berbuat kebaikan. Kewajban berbuat ihsan ini juga dikuatkan dengan firman Allah SWT dalam Al-Qur'an surat AlBaqarah:195. Bahwa ihsan itu bagaimana manusia berbuat dengan yakin beribadah seolah-olah melihat Tuhan, dan jika tidak mampu yakinlah bahwa Allah melihatmu. Inti dari ini bahwa al ihsan sebagai Al batin (ketenangan batin manusia).

Dari ketiga itu Al Iman, Al Islam, dan Al Ihsan dapat diambil bahwa idealnya pilar pilar profetik yang arahnya adalah muttaqin, muqorrobin, mu'ariffin yang dapat dijadikan manusia sarana atau wusul menjalankan perintah menjauhi larangan Allah SWT. 


\section{Qnd Proceedings \\ Annual Conference for Muslim Scholars KOPERTAIIS WILAYAH IV SURABATA \\ Reconstruction of Integrative Islamic Education Muhamad Khoirul Ulum - STAI Badrus Sholeh Kediri}

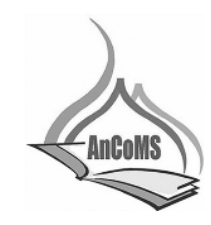

\section{INTEGRASI PENDIDIKAN ISLAM SAINTIFIC DEVELOPMENTS}

Bertolak dari rumusan UU Sistem Pendidikan Nasional RI No. 20 tahun 2003 pasal 339, yang mengisyaratkan bahwa tujuan pendidikan Indonesia mengarahkan warganya kepada kehidupan yang beragama. Maka sebagai salah satu bentuk realisasi dari UU Sisdiknas tersebut, integrasi adalah alternatif yang harus dipilih untuk menjadikan pendidikan lebih bersifat menyeluruh (integral-holistik). Gagasan integrasi (nilai-nilai Islami agama dan umum) ini bukanlah sebuah wacana untuk meraih simpatik akademik, melainkan sebuah kebutuhan mendesak yang harus dijalankan sebagai pedoman pendidikan yang ada, mengingat pendidikan selama ini dipengaruhi oleh dualisme yang kental antara ilmu-ilmu agama dan ilmu-ilmu umum/ sekuler yang menyebabkan dikotomi ilmu.

Pada era disrupsi keilmuan sekarang ini, atau yang disebut muncul dipermukaan berbagai macam proyek integrasi keilmuan baik itu yang disebut Islamisasi ilmu, integralisasi ilmu, ataupun integrasi-interkoneksi. Banyak gagasan pendidikan integratif melalui pendidikan profetik. Salah satu tawaran pemikiran tentang pendidikan alternatif yang diharapkan mampu mengurangi kebuntuan dalam mengembangkan pendidikan yang integratif dengan standar dan figur model yang benar-benar kuat dan tak terbantahkan yaitu Muhammad Saw dan kembali pada aktivitas, perasaan, pemikiran dalam memaknai Al-Quran dan Sunnah.

Pendidikan yang integratif merupakan bagian dari pengaktualisasian pendidikan profetik transformatif. Pendidikan profetik ini tidak akan berjalan tanpa membangun pendidikan yang integratif. Integratif dalam teori, desain, sistem, pelaksana, dan integratif dalam kelembagannya. Komunitas Muslim awal yang merupakan tim yang solid membawa kepada kejayaan masyarakat Muslim dalam arti yang utuh menyentuh keseluruhan sendi kehidupan. Sebagai contoh cara melakukan integrasi kurikulum yang menyentuh wilayah kognitif, afektif, dan psikomotorik adalah kurikulum yang memuat materi yang memicu kreativitas murid, sekaligus untuk meningkatkan daya sosialpsikologis seperti empati dan simpati peserta didik terhadap sesamanya.

Pendidikan dalam kerangka tradisi profetik merupakan pendidikan yang didesain dalam lembaga pendidikan Islam dengan menggunakan dasar filsafat dan budaya kenabian yang memiliki tiga pilar (transendensi, liberasi, dan humanisasi). pada basisnya tidak ada perbedaan dalam unsur subtansinya hanya beberapa hal yang harus memiliki karakteristik khusus. Tradisi kenabian jika menginternal dalam unsur-unsur pendidikan dapat dijelaskan sebagai berikut: ${ }^{10}$ I) prinsip integrasi (tauhid) yang memandang adanya wujud kesatuan dunia-akhirat; 2) prinsip keseimbangan. Prinsip ini merupakan konsekuensi dari prinsip integrasi; 3) prinsip persamaan dan pembebasan; 4) prinsip kontiuitas dan berkelanjutan;5) prinsip kesehatan dan keutamaan.

Materi pendidikan profetik minimal ada tiga prinsip dalam merancang materi: Pertama, pengembangan pendekatan religius kepada semua bidang ilmu pengetahuan. Kedua, isi pelajaran yang bersifat religius seharusnya bebas dari ide dan materi yang jumūd dan tidak bermakna. Ketiga, perencanaan dengan memperhitungkan setiap komponen yang disebut sebagai tiga prinsip: kontinuitas/kesinambungan, sekuensi, dan

${ }^{10}$ Moh. Roqib, Filsafat Pendidikan Profetik..., 125-151. 
integrasi. ${ }^{11}$ Dengan tujuan yang jelas dapat mempermudah mengambil langkah operasional dalam proses pendidikan termasuk penentuan materi.

Pendidik mempunyai peran besar dan strategis dalam memberikan output dalam proses pendidikan. Oleh karena itu ada beberapa syarat kepribadian yang harus dimiliki pendidik yang profetik adalah: I) zuhud dan ikhlas, 2) bersih lahir batin, 3) pemaaf, sabar, dan mampu mengendalikan diri, 4) bersifat kebapakan atau keibuan, 5) mengenal peserta didik dengan baik (individu maupun kolektif). Kepribadina pendidikan harus merupakan refleksi dari nilai- nilai Islam.

Metode pendidikan yang profetik dapat dimaknai sebagai metode yang dihasilkan dari hadist atau sunnah nabi dan perilaku sosialnya kepada anak- anak. Selain itu juga, dari dialog langsung yang nabi lakukan kepada anak-anak atau kepada orang tua tentang cara memperlakukan anak-anak mereka. ${ }^{12}$ Seyogyanya tidak ada perbedaan antara metode pendidikan profetik dengan pendidikan yang lain. Yang membedakan hanya pada nilai spiritual dn mental yang menyertai pada saat metode tersebut dilaksanakan. Prinsip tersebut juga dimungkinkan ada kesamaan dengan prinsip metode pendidikan lain meskipun secara prinsip tetap ada unsur- unsur pembedanya.

\section{IMPLEMENTASI PENDIDIKAN KENABIAN BERSINERGI CULTURE PSICHOLOGY TRANSFORMATIONAL}

Pendidikan Islam dalam aplikasi budaya sangat diperlukan sebagai bagian dari pembentukan jati diri manusia melalui lingkungan dengan lambang pendidikan religius yang dimilikinya. Bahkan, dalam Islam diperlukan pengkayaan lambang budaya sebab lambing yang sebagai symbol budaya akan lebih mudah diterima ketimbang agama, termasuk di zaman post-colonial atau dalam istilah teori kritis post-modern. keanekaragaman budaya masyarakat Indonesia adalah suatu bentuk potensi ekonomi lokal kreatif yang ikut menentukan masa depan bangsa. Budaya sebagai bahan tinjauan kajiannya hal ini dapat memunculkan sifat menerima, melestarikan. Sebab pendidikan sendiri adalah salah satu sebuah produk peradaban budaya. Sehingga kebudayaan dan pendidikan merupakan mata rantai yang saling bertautan, mengisi, dan di antaranya mempunyai hubungan intern relative.

Pendidikan profetik tentunya punya efek transformasi bukan hanya pada tataran sosial-budaya tetapi juga pada tataran individu. Bahkan transformasi individual inilah yang semestinya lebih dahulu terjadi sebelum transformasi-transformasi yang lain. Menoleh sedikit cara pandang psikologi perkembangan yang mana menampilkan objeknya yaitu pada perkembangan manusia sebagai pribadi individu. Perkembangan pribadi manusia ini berlangsung sejak konsepsi sampai death yang selaras dengan tujuan pendidikan Islam. Perkembangan yang dimaksudkan adalah proses tertentu yang terus menerus, dan proses yang menuju ke depan dan tidak begitu saja dapat diulang kembali.

\footnotetext{
${ }^{11}$ Syed Ali Ashraf dan Syed Sajjad Husein, Krisis Pendidikan Islam, terj. Rahmani Astuti (Bandung: Risalah, 1986), hal. 41-42.

${ }^{12}$ Muhammad Nur Abdul Hafizh Suwaid, Prophetic Parenting (Yogyakarta: Pro-U Media, 210), terj, hal. 138.
} 


\section{Qnd Proceedings \\ Annual Conference for Muslim Scholars KOPERTAIIS WILAYAH IV SURABATA

Pada teori psikodinamika perubahan mengatakan bahwa perkembangan jiwa atau kepribadian seseorang ditentukan oleh komponen dasar yang bersifat sosio efektif, yakni ketegangan yang ada dalam diri seseorang itu ikut menentukan dinamikanya di tengah lingkungannya sendiri. Unsur subtansi yang mempengaruhinya adalah motivasi, emosi,dan aspek-aspek internal lainnya. Para ahli teori ini percaya bahwa perkembangan merupakan suatu proses aktif dan dinamis yang sangat dipengaruhi oleh dorongandorongan atau impuls individual yang dibawa sejak lahir serta pengalaman-pengalaman sosial dan emosional mereka. ${ }^{13}$

Berdasarkan pada analitis kritis psikologi sangat jelas tergambarkan bahwa setiap pribadi individual manusia selalu bertransformasi dan berkembang sesuai dengan pengalaman yang didapatnya. Pengalaman yang memberikan perubahan adalah pendidikan, semakin baik dan bagus pendidikan maka bagus pula indivu-individunya. Transformasi individual yang dihasilkan oleh pendidikan profetik ini bisa dua macam yaitu I) diri ilmuan profetik, dan 2) individu yang menjadi kajian keilmuan profetik tertentu.

Dari pendidikan profetik, nantinya pada setiap cabang kelimuan yang lain juga berdasar pada landasan profetik misalnya psikologi profetik dan kedokteran profetik. Ilmu kedokteran profetik akan melahirkan transformasi individual pada ranah ragawi (physical) yang kemudian akan dapat menghasilkan transformasi pada tataran masyarakat. Disiplin profetik lainnya, yaitu psikologi profetik dapat menghasilkan transformasi pada ranah kejiwaan (psychological) individual, yang kemudian akan mencapai ranah kolektif juga, memunculkan sifat-sifat yang sehat misalnya tidak hadir sifat kesombongan.

Sehingga konsep pendidikan profetik-integratif nantinya adalah pendidikan yang terbuka dan menerima beragam aktivitas keilmuan lainnya seperti ilmu-ilmu alam (natural science), ilmu-ilmu sosial (social science), humaniora, dan IPTEK dengan basis budaya atau berdasarkan tradisi. Dengan demikian tidak menjadikan sikap dan sifat manusia yang sekuler, hedonis, atau materialis karena keagamaan manusia yang menyatu dalam satu tarikan nafas keilmuan dan keagamaan, serta mempunyai sifat arif karena memahami kebudayaan yang ada. Melalui konsep ini menghadirkan akan pentingnya pembiasaan, kultur, atau budaya yang harus ditumbuh kembangkan secara terus menerus. Semua itu demi kesejahteraan manusia secara bersama-sama tanpa pendang latar belakang etnisitas, agama, ras, maupun golongan.

\section{SIMPULAN}

Profetik berarti sifat nabi yang mempunyai ciri sebagai manusia yang ideal secara spiritual-individual, tetapi juga menjadi pelopor perubahan, membimbing masyarakat ke arah perbaikan dan melakukan perjuangan tanpa henti melawan penindasan, profetik juga merupakan sesuatu yang berhubungan dengan nilai-nilai kenabian yang secara definitif nilai profetik dapat dipahami sebagai esensi yang melekat pada sesuatu yang sangat berguna bagi kehidupan manusia seperti halnya sifat nabi.

\footnotetext{
${ }^{13}$ Makmun Khairani, Psikologi Perkembangan (Yogyakarta: Aswaja Pressindo, 2013), 36.
} 


\section{Qnd Proceedings \\ Annual Conference for Muslim Scholars \\ KOPERTAIIS WILAYAH IV SURABAYA}

Reconstruction of Integrative Islamic Education

Muhamad Khoirul Ulum - STAI Badrus Sholeh Kediri

Pendidikan berdasarkan nilai-nilai Islam dapat berupa pendidikan yang secara faktual berusaha menghadirkan nilai kenabian dalam konteks kekinian yang berorientasi untuk membangun komunitas sosial yang ideal (khairu ummah) dan dibangun melalui pilar transendensi yang kuat berpengaruh pada seluruh dimensi dan sistem pendidikan yang dibarengi pilar humanisasi yang membangun nilai atas asas kemanusiaan dan liberasi yakni mengurangi bentuk-bentuk hal yang merusak kepribadian.

Pendidikan profetik dari ketiga pilar transendensi, liberasi, dan humanisasi bersentral pada objek budaya atau menyapa alam secara kreatif dan apresiatif terhadap local wisdom yakni pengintegrasian ilmu, agama, dan budaya yang terdesain rapi secara konseptual dalam tradisi edukasi, sehingga pendidikan akan bergerak dinamis dan proaktif terhadap tuntutan hidup ke depan untuk mewujudkan goalnya pendidikan profetik adalah mewujudkan kehidupan sosial yang ideal (khairu ummah).

Upaya pengintegrasian dengan pendidikan kenabian dapat dilakukan dengan setiap kelembagaan pendidikan berhasrat ke arah terbentuknya religious culture. Pemikiran ini kiranya mengandaikan suatu bentuk perpaduan sejati dengan simbol ketokohan Muhammad SAW antara ilmu, agama, dan budaya atau lebih singkatnya antara agama dan sains, yang dapat mensinergikan secara fleksible, dan tentu saja link and match. Ini dimaksudkan agar civitas akademika lembaga pendidikan sebagai masyarakat kecil tidak lemah menghadapi kehidupan, memilih kesempatan dan lapangan kerja serta relasi hidup dalam masyarakat global (global community).

\section{DAFTAR PUSTAKA}

Adz-Dzakiey, Hamdani Bakran. 2007. Prophetic Psychology: Psikologi Kenabian Menghidupkan Potensi dan Kepribadian Kenabian dalam diri. Yogyakarta: Pustaka Al Furqon.

Az-Zain, Muhammad Basyam Rusydi. 2007. Sekolah Para Nabi I \& 2. Yogyakarta: Pustaka Marwa.

Dagum, M. 2006. Kamus Besar Ilmu Pengetahuan. Jakarta: Lembaga Pengkajian Nusantara.

Husein, Syed Ali Ashraf dan Syed Sajjad. 1986. Krisis Pendidikan Islam, terj. Rahmani Astuti. Bandung: Risalah.

Khairani, Makmun. 20I3. Psikologi Perkembangan. Yogyakarta: Aswaja Pressindo.

Ma'arif, Ahmad Syafii. 2009. Islam dalam Bingkai Kemanusiaan dan Keindonesiaan. Bandung: Mizan.

Mujtahid. 20I I. Tujuh Karakteristik Kepemimpinan Profetik. Malang: UIN Maliki.

Roqib, Moh. 2016. Filsafat Pendidikan Profetik: Pendidikan Islam integrative dalam Persfektif Kenabian Muhamad. Purwokerto: An-najah Press.

Shari'ati, Ali. 1996. Humanisme: Antara Islam dan Mazhab Barat, terj. Husein Anis alHabshi. Bandung: Pustaka Indah.

Suwaid, Muhammad Nur Abdul Hafizh. 2010. Prophetic Parenting. Yogyakarta: Pro-U Media. 